\title{
Optimalisasi Pemanfaatan Sekam Padi Menjadi Briket Arang Sekam untuk Menambah Pendapatan Petani di Desa Sukamaju, Jawa Barat
}

\section{Optimizing the Utilization of Rice Husk into Husk Charcoal Briquettes to Increase Farmers' Income in Sukamaju Village, West Java}

\author{
Nanang Ali Sutisna ${ }^{1 \bullet}$, Filda Rahmiati ${ }^{2}$, Grace Amin² \\ ${ }^{1}$ Program Studi Teknik Mesin, Universitas Presiden \\ ${ }^{2}$ Program Studi Manajemen, Universitas Presiden \\ `Email korespondensi: nanang.ali@president.ac.id
}

\begin{abstract}
One effort to increase farmers' income is by processing rice waste into a product that has selling value such as charcoal or briquettes. Husk charcoal has many benefits both in the agricultural world and for industrial needs. Rice husks from abundant harvests are usually burned by some farmers to be used as fertilizer, some are sold directly at very cheap prices. Based on these problems, an idea emerged to make equipment for processing rice husks into products with higher selling value. Charcoal briquettes can be used for cooking, lighting and industrial needs. The research was begun by holding a meeting with the farming community in Desa Sukamaju, Kecamatan Tambelang, Kabupaten Bekasi to find out the real conditions in the field and gathering necessary data. The next process is to make the rice husk charcoal maker and the charcoal briquette machine. The design of the charcoal maker is carried out to make charcoal by considering the airflow during charring in order to produce a faster time and reduce the spread of smoke, while the design of the charcoal briquette pressing machine is carried out calculating the strength of the required machine components. After the equipment needed was completed, a trial was conducted and the results showed that the charcoal making process takes 20-30 minutes for $10 \mathrm{~kg}$ of husks. Meanwhile, the calculation of the components of the pressing machine shows that the pressing machine is safe to use. Observations found that currently husk is valued at Rp. $1000 \mathrm{per} \mathrm{kg}$, and husk charcoal at Rp. 3000 to $R p .5000$ per kg, while the selling price of husk charcoal briquettes can reach Rp. 15,000 per kg. Thus, processing rice husks into charcoal briquettes is economically more profitable for farmers.
\end{abstract}

Keywords: briquette press machine, charcoal briquettes, farmer's income, rice husk,

\begin{abstract}
Abstrak. Salah satu upaya untuk menambah pendapatan para petani adalah dengan mengolah limbah padi menjadi suatu produk yang memiliki nilai jual seperti arang sekam atau briket. Arang sekam memiliki banyak manfaat baik di dunia pertanian maupun untuk kebutuhan industri. Sekam padi dari hasil panen yang berlimpah, oleh sebagian petani biasanya dibakar untuk dijadikan pupuk, ada juga yang dijual langsung dengan harga yang sangat murah. Berdasarkan permasalahan tersebut, muncul ide untuk membuat alat-alat untuk memproses sekam padi menjadi produk yang bernilai jual lebih tinggi, yaitu untuk pembakaran sekam menjadi arang sekam yang kemudian diolah lebih lanjut menjadi produk akhir berupa briket. Briket arang dapat dimanfaatkan untuk kebutuhan memasak, penerangan, maupun industri. Penelitian ini diawali dengan mengadakan pertemuan dengan komunitas petani di Desa Sukamaju, Kecamatan Tambelang, Kabupaten Bekasi untuk mengetahui kondisi dilapangan dan mengumpulkan data yang dibutuhkan. Proses berikutnya adalah merancang dan membuat alat pembuat arang sekam dan mesin pencetak arang sekam menjadi briket. Rancangan alat pembuat arang dilakukan untuk membuat arang dengan mempertimbangkan aliran udara saat pengarangan agar menghasilkan waktu yang lebih cepat dan mengurangi penyebaran asap, sedangkan pada perancangan mesin cetak briket arang dilakukan perhitungan kekuatan komponen mesin cetak yang diperlukan. Setelah alat yang dibutuhkan selesai, dilakukan uji coba alat dan hasilnya memperlihatkan bahwa proses pembuatan arang membutuhkan waktu 20-30 menit untuk $10 \mathrm{~kg}$ sekam. Sedangkan hasil perhitungan komponen mesin cetak menunjukkan bahwa mesin cetak aman untuk digunakan. Hasil observasi menemukan bahwa saat ini sekam dihargai Rp 1000 per kg, dan arang sekam Rp 3000 sampai Rp 5000 per kg, sedangkan harga jual briket arang sekam bisa mencapai Rp 15.000 per kg. Dengan demikian, pengolahan sekam padi menjadi briket arang secara ekonomis akan lebih menguntungkan bagi para petani.
\end{abstract}

Kata kunci: briket arang, mesin cetak briket, pendapatan petani, sekam padi. 


\section{PENDAHULUAN}

Kabupaten Bekasi mempunyai curah hujan cukup bervariasi. Begitu juga dengan bentuk wilayah kabupaten ini sebagian besar mempunyai relief datar sehingga pada umumnya masyarakat sekitar memanfaatkan keadaan ini dengan melakukan kegiatan bertani padi di sawah, menanam palawija juga kebun campuran. Keadaan ini membuat Kabupaten Bekasi menjadi salah satu sentra padi di wilayah Pantai Utara Jawa (Pantura) (Suparni, 2020). Salah satu desa yang memang menjadi wilayah pengembangan pertanian padi adalah Desa Sukamaju, Kecamatan Tambelang.

Desa Sukamaju adalah salah satu desa yang wilayahnya didominasi persawahan. Mata pencaharian sebagian besar masyarakat di sana adalah bertani di sawah. Para petani akan memanen padi setiap 4 bulan sekali atau setidaknya 2 kali dalam setahun, tergantung pada ketersediaan air. Untuk mendukung proses pengolahan padi, terdapat cukup banyak tempat penggilingan. Menurut salah satu pemilik penggilingan yang peneliti wawancarai, setidaknya terdapat 10 tempat penggilingan di desa Sukamaju. Setelah masa panen, biasanya akan terdapat banyak sisa dari penggilingan berupa limbah kulit padi (sekam). Limbah sekam yang kurang dikelola akan dengan mudah tertiup angin dan mengganggu lingkungan serta kesehatan masyarakat sekitar. Untuk mencegah pencemaran lingkungan akibat sekam yang tidak dikelola dengan baik maka sekam padi dapat dimanfaatkan menjadi bahan bakar alternatif pengganti minyak tanah, gas, atau arang kayu dan juga diolah menjadi pupuk organic yang ramah lingkungan (Baderan \& Hamidun, 2016). Akan tetapi, limbah belum dimanfaatkan dengan baik, seperti limbah sekam padi, di masa mendatang diperlukan pemanfaatan limbah tersebut secara efisien (Suryaningsih, Resitasari, \& Nurhilal, 2019).

Kurangnya pengetahuan dan ketrampilan petani dalam pemanfaatan limbah dan rendahnya tingkat pendapatan menjadi permasalahan Desa (Sulmiyati, 2017).

Berdasarkan hasil wawancara juga observasi yang dilakukan oleh tim peneliti, Desa Sukamaju belum dapat memanfaatkan secara maksimal limbah sekam padi dari hasil penggilingan. Jumlah sekam yang dihasilkan oleh petani jumlahnya tidak sedikit. Dari hasil pengamatan awal, dari $100 \mathrm{~kg}$ gabah kering akan dihasilkan kirakira $20 \mathrm{~kg}$ sekam, jika 1 ha sawah menghasilkan rata-rata 4 ton gabah kering panen berarti sekam yang dihasilkan sekitar 8 kwintal sekam. Luas lahan pertanian di desa Sukamaju adalah 501 ha (Badan Pusat Statistik Kabupaten Bekasi, 2018) , maka total sekam yang dihasilkan adalah 400,8 ton. Satu lokasi penggilingan saja sudah menghasilkan banyak sekam padi yang mudah tertiup angin dan mencemari lingkungan. Dapat dibayangkan jika 10 lokasi penggilingan di Desa Sukamaju kurang mampu mengelola limbah tersebut maka akan sangat mempengaruhi lingkungan dan kesehatan masyarakat di sana.

Mengacu pada kurang optimalnya pemanfaatan sekam padi oleh masyarakat di Desa Sukamaju, maka diperlukan adanya kegiatan yang diharapkan dapat memberikan dampak positif terhadap lingkungan, kesehatan dan perekonomian masyarakat di sana. Pemanfaatan arang sekam dapat memberikan pendapatan tambahan, memperbaiki lahan pertanian, dan pelestarian lingkungan. yang mampu mendukung perekonomian masyarakat di Desa Sukamaju (Rahmiati et al., 2019). Arang sekam dapat diolah lebih lanjut dengan menambahkan perekat dan mencetaknya menjadi briket arang. Briket arang ini dapat dijual dan digunakan untuk kebutuhan memasak, penerangan, maupun industri

Mesin pencetak briket arang sekam telah banyak dibuat oleh beberapa industri pembuat mesin, namun sebagian besar 
menggunakan tenaga hidrolik (Cahyono, 2017) dan harganya relatif mahal.

Penelitian ini bertujuan untuk memberikan solusi untuk masyarakat petani dengan membuatkan alat pembuat arang sekam yang lebih efisien dan mesin pencetak briket arang sekam yang sederhana dan terjangkau, sehingga arang sekam padi memiliki nilai jual yang lebih tinggi.

\section{METODE}

Sasaran dalam kegiatan ini adalah mitra yang bergerak di bidang ekonomi produktif. Metode pelaksanaan yang dilakukan menyangkut dua bidang yang sesuai dengan prioritas permasalahan yang dihadapi, yaitu produksi dan pemasaran hasil produksi. Berdasarkan persoalan tersebut maka tahapan pelaksanaan program yang dilakukan peneliti adalah sebagai berikut:

\section{Survei lapangan}

Dalam tahap pertama ini, peneliti melakukan observasi langsung ke Desa Sukamaju untuk mengetahui situasi maupun permasalahan yang mereka hadapi. Peneliti juga melakukan wawancara dengan beberapa pihak seperti masyarakat sekitar, para petani serta pejabat pemerintah di Desa Sukamaju. Informasi dari hasil wawancara dan survei tersebut kemudian menjadi acuan peneliti untuk mencari sumber referensi serta merancang kegiatan selanjutnya.

\section{Perancangan dan pembuatan alat pembuat arang sekam}

Peneliti merancang dan membuat alat bantu yang dapat mengolah sekam padi menjadi arang sekam yang lebih efisien dengan tetap memperhatikan polusi udara. Proses pembakaran sekam padi diatur sedemikian rupa agar asap yang dihasilkan tidak mengganggu lingkungan. Alat pembakaran sekam padi menggunakan cerobong asap yang cukup tinggi sehingga asap yang dihasilkan dari proses pembakaran tersebut tidak terlalu mengganggu. Kemudian peneliti mengolah serbuk arang sekam padi tersebut dengan mencampurkannya dengan perekat tepung tapioka (kanji) sehingga menjadi lebih padat dan dapat dibentuk.

\section{Perancangan dan Pembuatan Mesin cetak briket arang sekam}

Selanjutnya, peneliti merancang dan membuat mesin cetak briket arang sekam. Mesin ini dapat mencetak arang sekam yang telah dicampurkan dengan tepung tapioka menjadi briket sesuai bentuk dan ukuran yang diinginkan.

\section{Uji coba pembuatan arang sekam dan briket arang sekam.}

Setelah alat pembuat arang dan mesin pencetak briket arang sekam selesai dibuat, dilakukanlah uji coba pembuatan arang sekam dan pencetakan briket arang sekam di laboratorium kampus untuk melihat efisiensi proses pengarangan dengan tungku arang yang dibuat dan proses pencetakan briket arang. Dalam penelitian ini tidak dilakukan pengukuran nilai kalor hasil pembakaran briket arang sekam.

\section{HASIL DAN PEMBAHASAN}

\section{Survei Lapangan}

Berdasarkan hasil wawancara juga observasi yang dilakukan oleh peneliti, Desa Sukamaju belum dapat memanfaatkan secara maksimal limbah padi dari hasil penggilingan. Sekam yang dihasilkan dari proses penggilingan di satu tempat penggilingan padi sangat berlimpah ruah (Gambar 1). Dari hasil pengamatan awal kegiatan ini, dari $100 \mathrm{~kg}$ gabah kering akan dihasilkan kira-kira $20 \mathrm{~kg}$ sekam, jika $1 \mathrm{Ha}$ sawah menghasilkan rata-rata 4 ton gabah kering panen berarti sekam yang dihasilkan sekitar 8 kwintal sekam. Mengingat luas lahan pertanian di desa Sukamaju adalah 501 ha maka total sekam yang dihasilkan adalah 400,8 ton, sedangkan seluruh luas 
lahan pertanian di Kecamatan Tambelang adalah sekitar 2.954 Ha maka akan dihasilkan 11.800 ton gabah kering yang akan menghasilkan limbah 2.360 ton sekam. Apabila hal ini dibiarkan maka sekam yang tidak diolah ini dapat tertiup angin dan mencemari lingkungan. Pada dasarnya sekam merupakan produk sampingan yang bisa ditingkatkan nilai jualnya. Nilai jual sekam yang tidak diolah lebih lanjut adalah Rp 1000 per kg dan jika diolah menjadi briket arang maka nilai jualnya bisa mencapai $\mathrm{Rp} 15.000$ per kg.

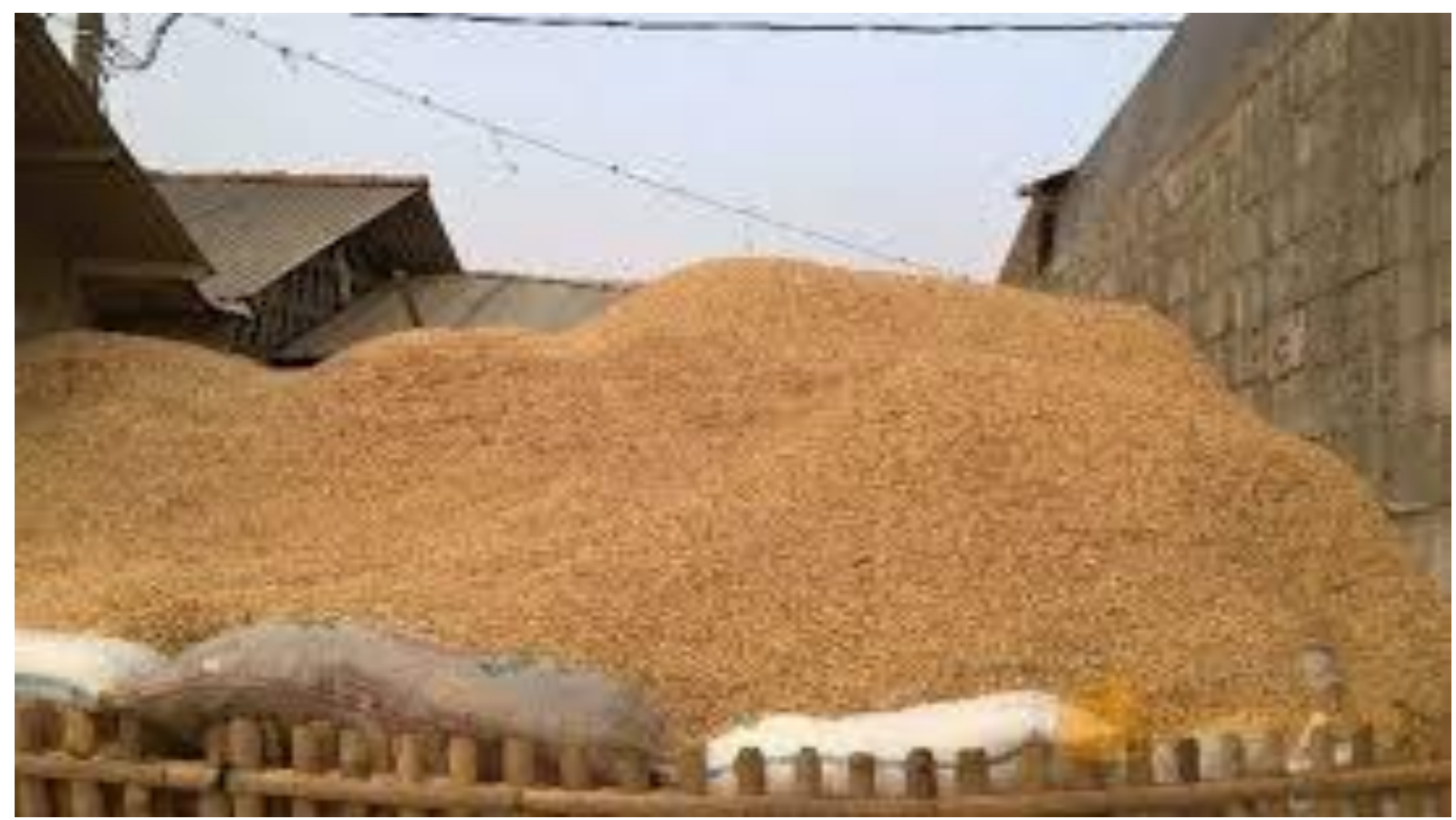

Gambar 1. Sekam sebagai hasil sampingan pertanian jumlahnya melimpah

Salah satu cara meningkatkan nilai sekam adalah dengan dibuat arang yang nantinya dapat dimanfaatkan sebagai media tanam. Pembuatan arang sekam secara tradisional, pada umumnya dilakukan dengan membakar sekam dengan cerobong (bisa terbuat dari pelat yang dilubangi atau kawat kasa yang digulung) di tempat terbuka sebagaimana diperlihatkan pada Gambar 2 (Rahmiati et al., 2019). Cara ini adalah yang paling murah dan praktis dibandingkan dengan menggunakan tabung tertutup (kiln) yang membutuhkan biaya lebih besar. Lama waktu pengarangan secara tradisional dapat mencapai 3-4 jam.

Persoalan yang timbul dari cara pembuatan arang sekam dengan cerobong kawat kasa adalah asapnya menyebar di tempat yang rendah sehingga mengganggu lingkungan sekitarnya (lihat Gambar 2), sehingga perlu dilakukan cara yang lebih baik agar asap dari proses pengarangan tidak mengganggu lingkungan.

\section{Perancangan dan Pembuatan Alat Pembuat Arang Sekam}

Untuk mengurangi penyebaran asap ke lingkungan sekitar dapat dilakukan adalah dengan merancang cerobong tinggi dan tertutup sekelilingnya untuk menjaga asap agar tidak menyebar di tempat rendah. Maka dari itu perlu adanya alat yang lebih baik lagi menjaga lingkungan sekitar. 


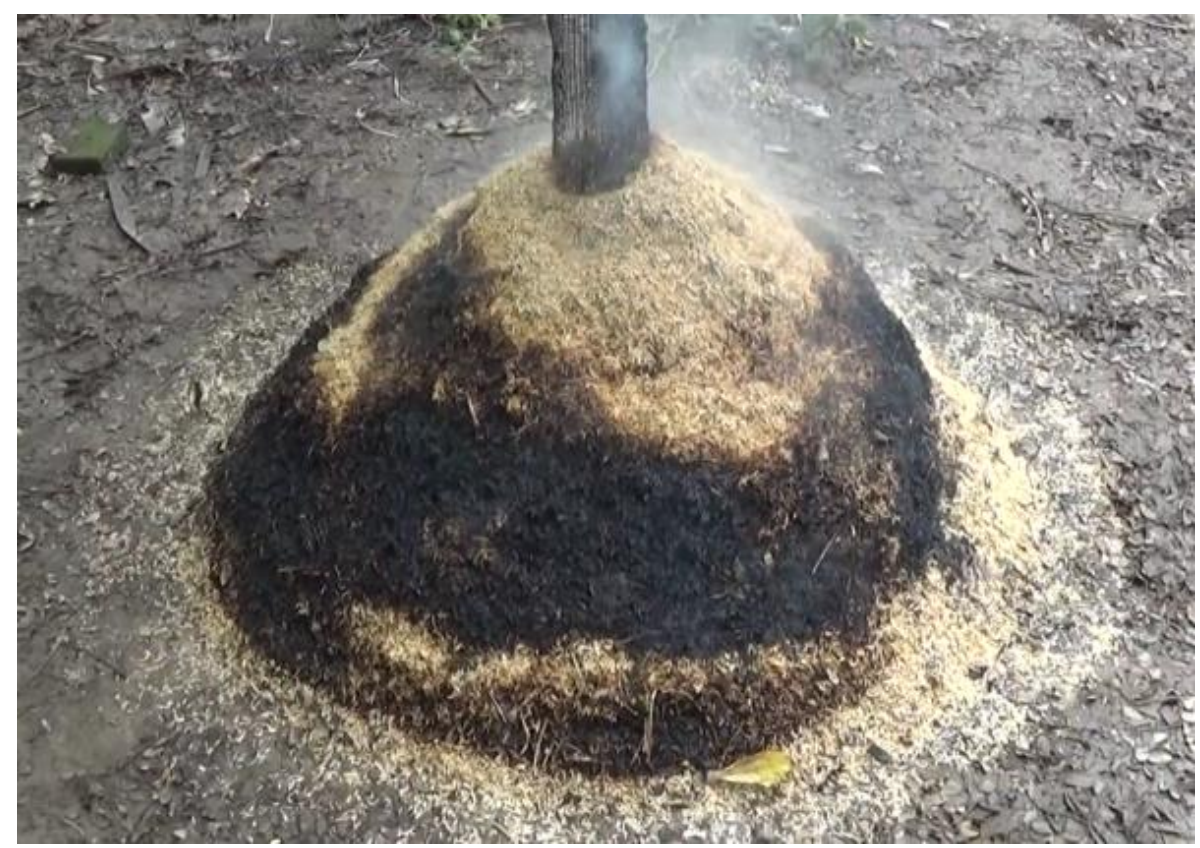

Gambar 2. Proses pembuatan arang sekam padi secara tradisional

Rancangan tungku api berbentuk kerucut sehingga penyebaran api ke sekam lebih baik. Mekanisme pembentukan arang sekam padi dapat terlihat pada Gambar 3, yaitu sebagai berikut:

- Api di bawah tungku mendorong udara dan asap ke atas cerobong, sehingga udara luar tertarik kedalam tungku

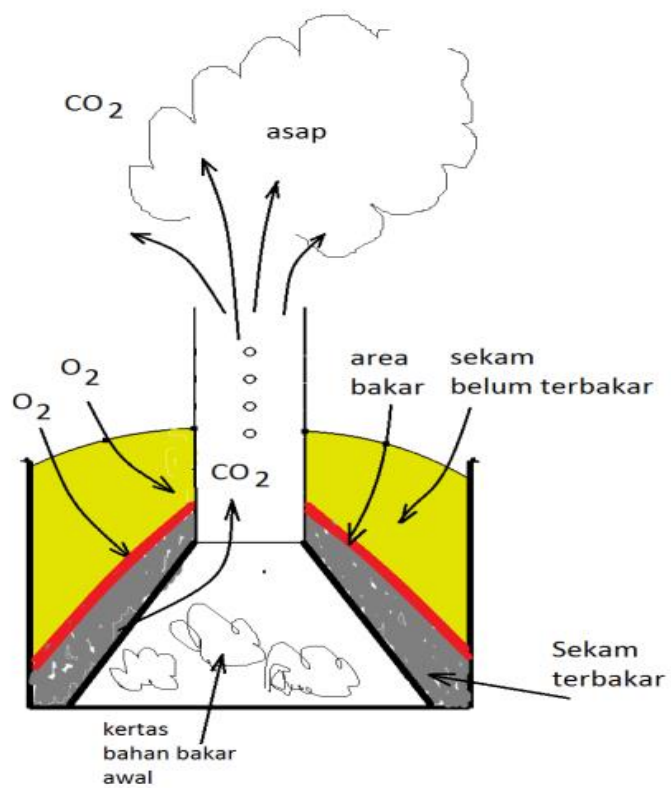

Gambar 3. Mekanisme pembentukan arang sekam melalui sekam yang belum terbakar.

- Sementara itu, sekam yang bersentuhan dengan tungku mulai terbakar dan mengkonsumsi oksigen. Pada saat area bakar merembet keluar, bagian dalam yang telah terbakar tidak mendapat oksigen sehingga tidak terbakar menjadi abu melainkan menjadi arang.

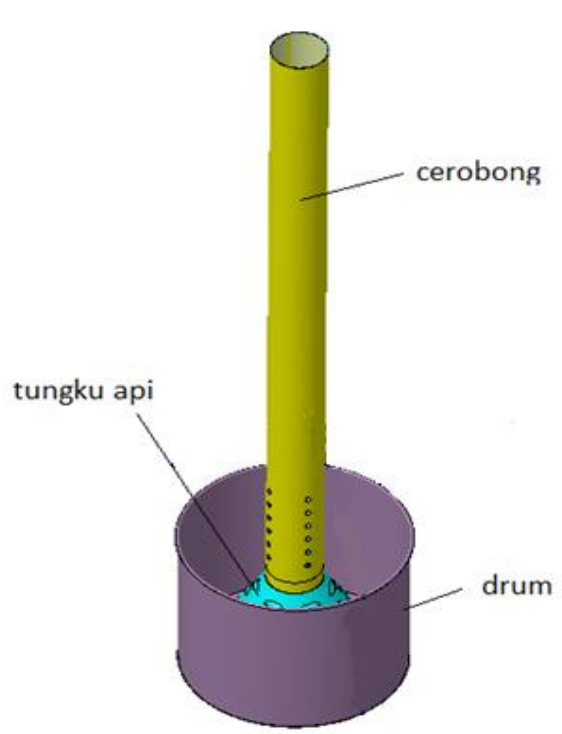

Gambar 4. Alat pembuat arang sekam padi 
Alat pembuat arang sekam padi ini terdiri dari 3 bagian, yaitu:

a. Drum penampung sekam

b. Tungku api

c. Cerobong asap

Drum penampung sekam terbuat dari bekas drum oli yang dipotong dua. Tungku api berbentuk kerucut dan berlubang ventilasi serta cerobong setinggi $2 \mathrm{~m}$ terbuat dari pelat baja dengan tebal $1 \mathrm{~mm}$.

Sedangkan penopang cerobong asap terbuat dari besi beton berdiameter $10 \mathrm{~mm}$. Gambar rancangan bagian-bagian alat pembuat arang ini ditunjukkan pada Gambar 4. Dengan alat ini, asap yang terbentuk dapat diarahkan dan arang yang terbentuk lebih mudah menempatkannya. Estimasi pengarangan adalah sekitar 30 menit.

Alat yang digunakan dalam fabrikasi alat pembuat arang sekam ini adalah mesin potong pelat, mesin rol pelat, mesin bor, dan mesin las TIG.

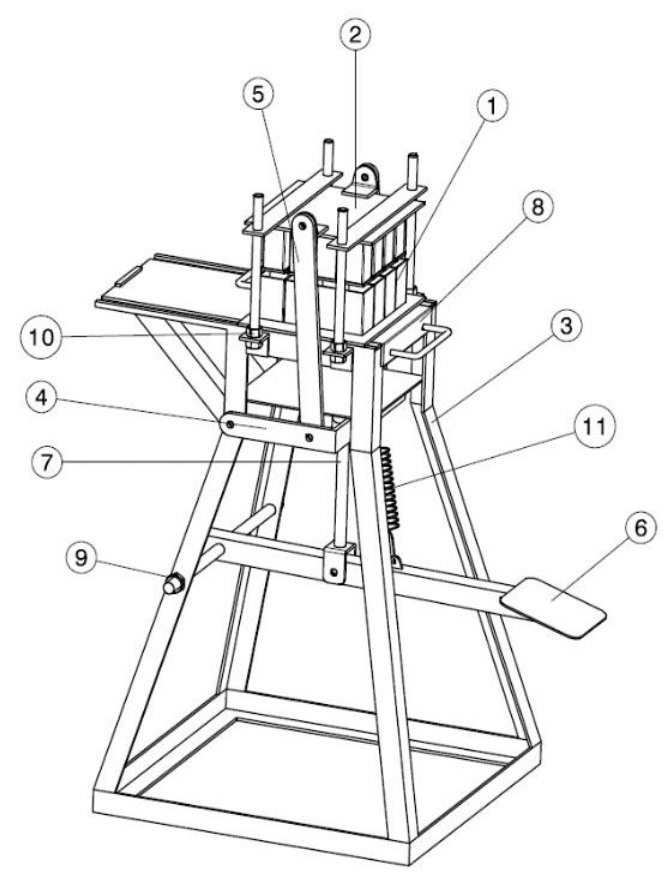

\section{Perancangan dan Pembuatan Mesin Cetak Briket Arang Sekam}

Untuk meningkatkan nilai ekonomisnya, hasil produksi arang sekam dapat diproduksi berupa briket arang untuk kebutuhan memasak, penerangan, maupun industry. Harga arang sekam per kg adalah Rp 3000 - 5000 sedangkan harga briket arang adalah antara Rp $15.000-20.000$ per $\mathrm{kg}$ (sebagai referensi adalah harga briket arang tempurung di Bukalapak). Sekam yang dihasilkan dari 1 ha sawah adalah sekitar 8 kwintal, sehingga potensi pendapatan masyarakat dari 1 ha lahan, dengan mengambil harga briket arang sekam terendah yaitu Rp 15.000 per $\mathrm{kg}$, adalah Rp 12.000.000. Mengingat luas lahan pertanian di desa Sukamaju adalah 501 ha maka potensi pendapatan dari penjualan briket arang sekam di Desa Sukamaju adalah Rp 6,012 miliar.

Selain dari itu, penelitian yang dilakukan oleh Papilo (2012) menyebutkan bahwa efisiensi yang dihasilkannya, briket diharapkan mampu menjadi salah satu solusi bahan bakar pengganti BBM yang murah dan ramah lingkungan.

Gambar 5. Mesin cetak briket arang sekam 
Mekanisme pembentukan arang sekam padi menjadi briket yaitu sebagai berikut arang yang sudah berbentuk serbuk tersebut dicampur dengan perekat yang terbuat dari tepung tapioka (kanji) dan kemudian dipres atau dicetak dalam mesin cetak untuk selanjutnya dikeringkan. Gambar 5 memperlihatkan rancangan mesin cetak briket yang dibuat.

\section{Perhitungan kekuatan komponen mesin cetak briket arang sekam}

Mesin cetak briket arang sekam ini hampir seluruhnya dibuat dengan menggunakan material SS400 (JIS G3101 : 1995) yang memiliki kekuatan tarik maksimum $=400-510$ Mpa dan kekuatan luluh $=235-245 \mathrm{Mpa}$. Sedangkan cetakan dan tuas penekan terbuat dari baja hollow segi empat berukuran 40x40 mm dengan tebal $2 \mathrm{~mm}$. Kekuatan luluh (yield strength) baja hollow ini adalah $162 \mathrm{Mpa}$ seperti terlihat pada Tabel 1.

Tabel 1. Properti material besi hollow segi 4 dasar SHS (Kadir et al., 2013)

\begin{tabular}{|c|c|c|}
\hline$\sigma_{\mathrm{y}}(\mathrm{MPa})$ & $\sigma_{\mathrm{u}}(\mathrm{MPa})$ & $\mathrm{E}(\mathrm{MPa})$ \\
\hline $\mathbf{1 6 2}$ & 300 & 81000 \\
\hline
\end{tabular}

Pada perhitungan komponen mesin cetak ini dilakukan menggunakan software CATIA V5 dengan metoda elemen hingga (Finite Element Method) yang hasilnya dapat dilihat pada gambar 6

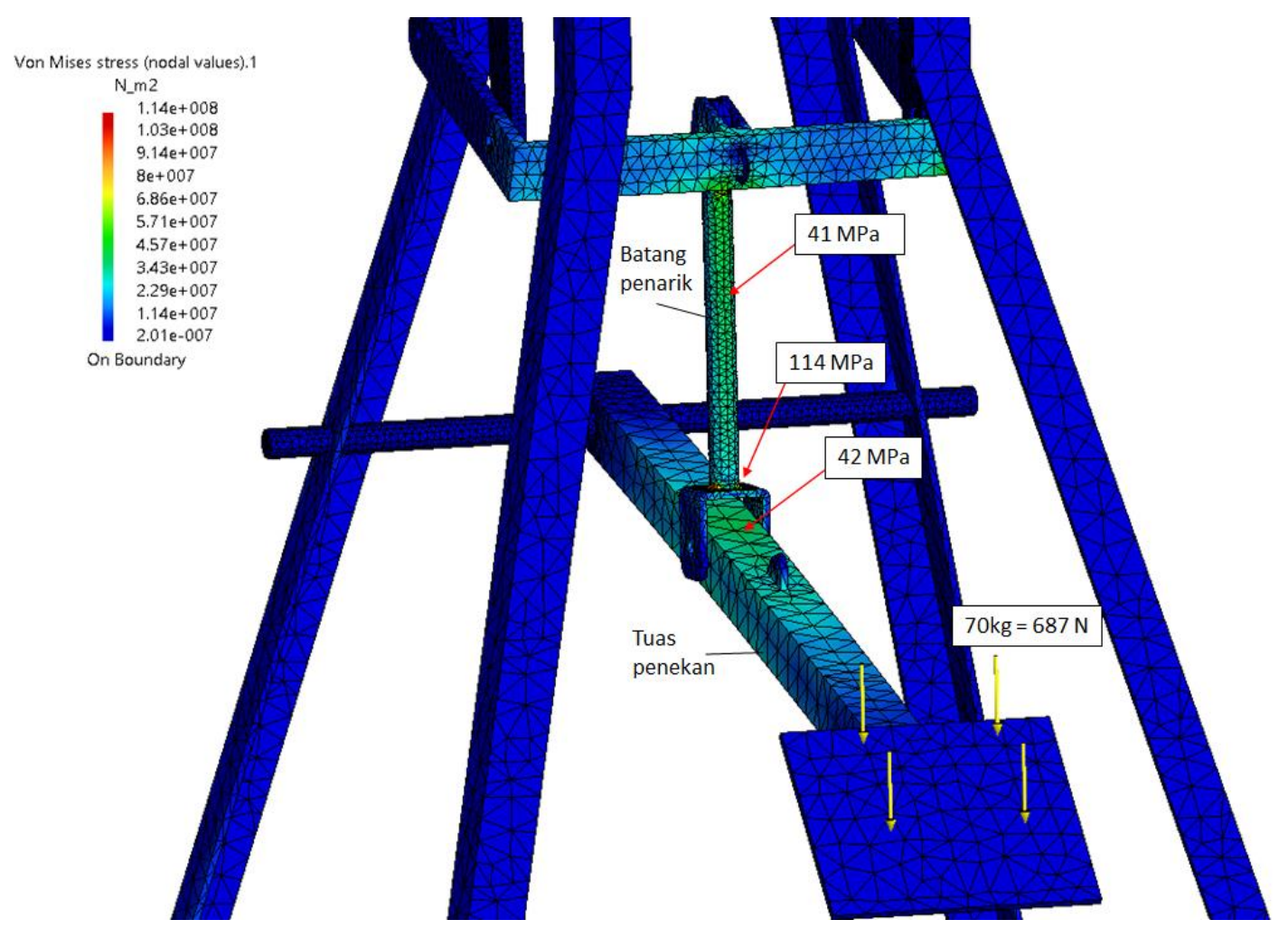

Gambar 6. Hasil simulasi software FEM

Dari hasil simulasi terlihat bahwa tegangan Von Mises maksimum yang terjadi adalah sebesar $114 \mathrm{MPa}$, yaitu di daerah sambungan las pada batang penarik. Sedangkan pada datang penarik sendiri hanya menerima tegangan sebesar $41 \mathrm{Mpa}$. Dengan memperhatikan Kekuatan luluh material SS400 sebesar 235 Mpa, maka komponen ini masih aman untuk dioperasikan karena tegangan yang terjadi lebih kecil dari tegangan luluhnya.

Demikian juga pada tuas penekan yang dibebani $70 \mathrm{~kg}$ atau $687 \mathrm{~N}$ mendapat tegangan Von Mises sebesar $42 \mathrm{Mpa}$, masih 
aman karena tuas yang terbuat dari besi hollow ini menderita tegangan kerja lebih kecil dari kekuatan luluh material besi hollow, yaitu $162 \mathrm{Mpa}$.

Selanjutnya adalah pemilihan pegas. Pegas berfungsi mengembalikan cetakan atas ke posisi semula. Dari perhitungan diperoleh faktor kekakuan pegas (spring rate) sebesar $1,54 \mathrm{~N} / \mathrm{mm}$, sehingga dipilihlah pegas no. 80701 dari produk CSC yang memiliki Spring Rate $1.6 \mathrm{~N} / \mathrm{mm}$ seperti terlihat pada Tabel 2 di bawah ini.

Tabel 2. Data pegas produksi CSC (MW Industries, Inc., 2020).

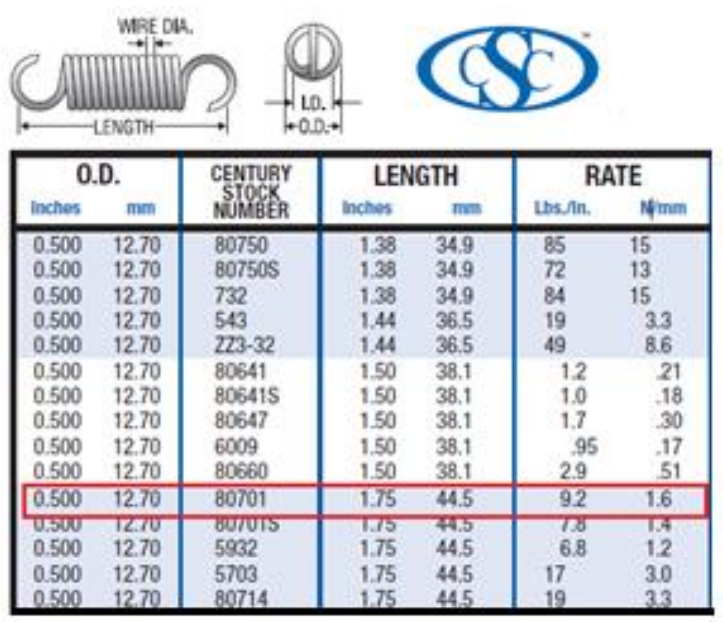

\section{Fabrikasi mesin cetak briket arang sekam padi}

Pada fabrikasi mesin cetak briket arang ini membutuhkan bahan sebagai berikut, (untuk nama komponen bisa dilihat pada Gambar 5):

- Baja siku 50x50x2 mm untuk rangka

- Baja hollow 50x50x2 mm untuk cetakan bawah (no. 1)

- Baja hollow 40x40x2 mm untuk cetakan atas (no. 2)

- Baja strip 40x40x5 untuk link no. 5

- Pelat dengan tebal $3 \mathrm{~mm}$ untuk alas cetakan (no. 8)

- Baja hollow 40x40x2 mm untuk tuas penekan
- Baja diameter $20 \mathrm{~mm}$ untuk poros no. 9 , batang penarik no 7 , dan pilar pengarah cetakan

Sedangkan alat dan mesin yang diperlukan adalah sebagai berikut:

- Mesin potong

- Mesin bor

- Mesin las

Mesin cetak briket arang sekam padi hasil fabrikasi dapat dilihat pada Gambar 7.

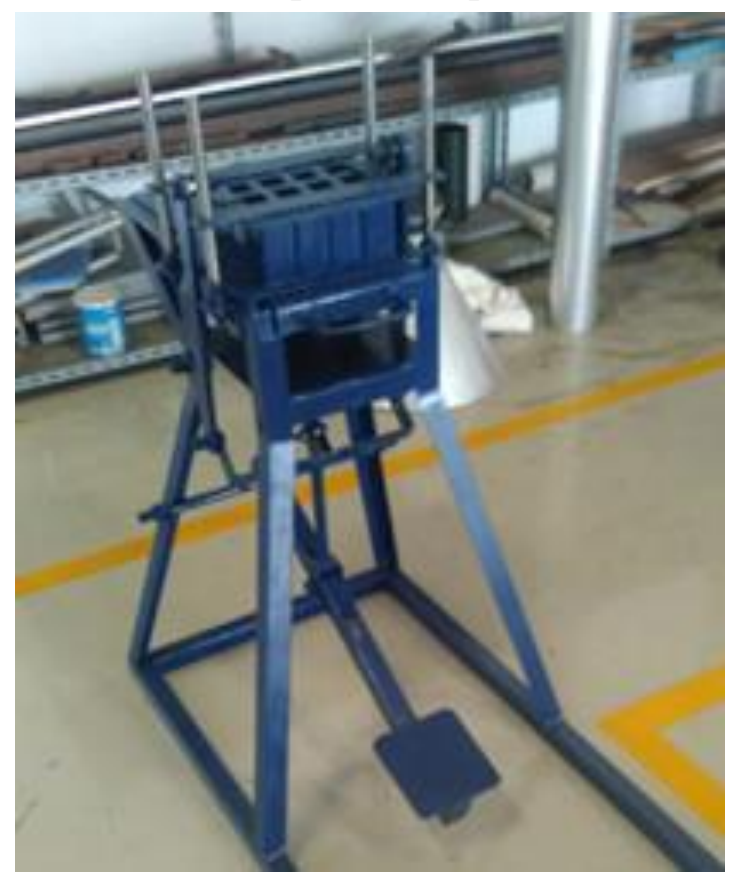

Gambar 7. Mesin cetak briket arang sekam

\section{Uji coba pembuatan arang sekam dan briket arang sekam}

Uji coba pembuatan arang sekam dengan alat pembuat arang dilakukan di laboratorium Fakultas Teknik Universitas Presiden dengan membakar sekam sebanyak $10 \mathrm{~kg}$ yang dimasukkan ke dalam drum. Hasil pembakaran menunjukkan bahwa dengan memproses $10 \mathrm{~kg}$ sekam diperlukan waktu rata-rata 25 menit untuk menjadi arang. Dibandingkan dengan metoda pengarangan lainnya maka pengarangan dengan alat ini lebih cepat, misalnya pengarangan sekam secara tradisional membutuhkan waktu 2-3 jam untuk $10 \mathrm{~kg}$ sekam (Rahmiati et al, 209) 
sedangkan pengarangan dengan menggunakan kiln drum membutuhkan waktu 100 menit untuk berat yang sama (Mandey \& Tarore, 2015).

Pada Gambar 8 terlihat bagaimana asap pembakaran sekam disalurkan melalui cerobong asap ke atas dan tidak menyebar di bawah.

Arang sekam yang dihasilkan kemudian dicampur dengan cairan perekat berbahan tepung tapioka dengan perbandingan 5 bagian arang berbanding 1 bagian perekat, untuk selanjutnya dicetak di mesin cetak briket arang yang dibuat di laboratorium Teknik Mesin. Gambar 9 memperlihatkan proses pencetakan briket dari arang sekam. Dalam sekali cetak dapat menghasilkan briket arang sekam seberat 1 kilogram.

Sebagai sumber energi, briket arang sekam memiliki nilai kalor yang cukup tinggi sebagaimana yang diungkapkan oleh (Patabang, 2012) bahwa bahwa nilai kalor briket arang sekam dengan konten bahan perekat $7 \%$ adalah $2789 \mathrm{kKal} / \mathrm{kg}$ sedangkan

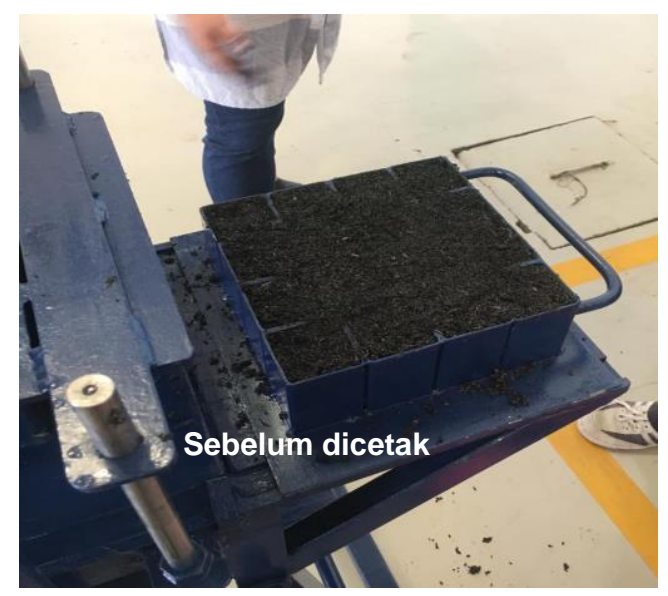

Gambar 9. Proses pencetakan briket arang sekam

Kegiatan pengolahan limbah untuk energi selain memberikan peluang untuk melestarikan lingkungan, pembangunan pedesaan, juga kepada bisnis. Dengan
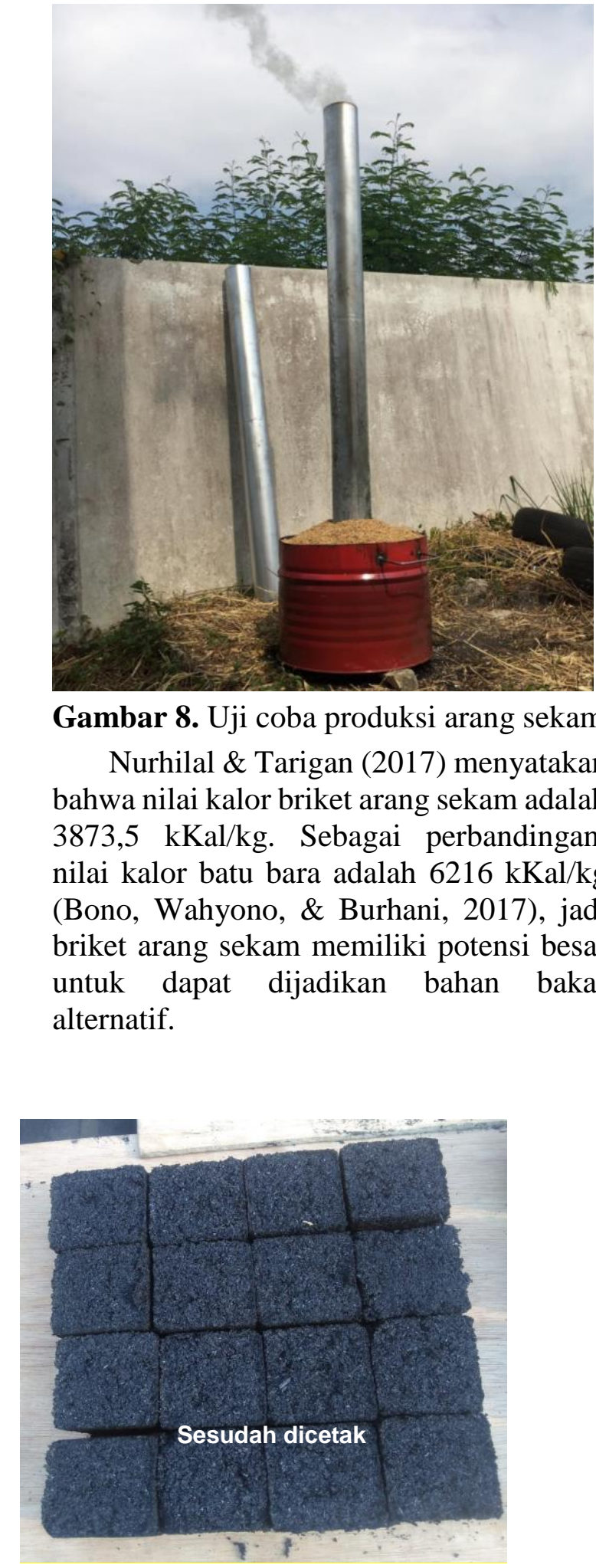

Gambar 8. Uji coba produksi arang sekam

Nurhilal \& Tarigan (2017) menyatakan bahwa nilai kalor briket arang sekam adalah $3873,5 \mathrm{kKal} / \mathrm{kg}$. Sebagai perbandingan, nilai kalor batu bara adalah $6216 \mathrm{kKal} / \mathrm{kg}$ (Bono, Wahyono, \& Burhani, 2017), jadi briket arang sekam memiliki potensi besar untuk dapat dijadikan bahan bakar alternatif.

melakukan kegiatan ini diharapkan dapat memberikan motivasi dalam menambah pendapatan para petani dan meningkatkan produktivitas para petani di Desa 
Sukamaju, Kecamatan Tambelang, Kabupaten Bekasi. Metode yang dilakukan, selain melalui penyuluhan, pelatihan dengan demonstrasi pengolahan briket, pembimbingan dan pendampingan menjadi produk yang siap dipasarkan juga penting (Sulmiyati, 2017).

Dengan kemampuan sekali cetak seberat $1 \mathrm{~kg}$ briket arang dalam waktu 4 menit, maka dalam 8 jam (sehari) akan dihasilkan $120 \mathrm{~kg}$ briket arang sekam. Dengan harga briket arang sekam sebesar $\mathrm{Rp} 15.000$ per $\mathrm{kg}$ maka sehari dapat menghasilkan Rp1.800.000. Dengan demikian, dengan perhitungan 1 bulan terdiri dari 25 hari kerja maka satu mesin cetak dapat menghasilkan Rp 45.000.000. Sementara itu, biaya pembuatan mesin cetak briket arang sekam ini cukup terjangkau oleh masyarakat yaitu sebesar Rp 6.800.000.

Setelah proses pembuatan alat dan para petani mampu untuk memproduksi produk arang sekam dan briket, diperlukan promosi dan pemasaran produk. Pemasaran produk dapat dilakukan secara offline maupun online melalui internet. Produk briket juga banyak diminati di negara2 lain seperti jepang, arab, turki, dan lainnya. Maka potensi ekspor briket sangat menjanjikan. Selain ekspor, penjualan briket juga dapat dilakukan ke restoran-restoran yang dulunya menggunakan arang kayu atau arang batok kelapa sekarang beralih ke briket.

Pemasaran produk dapat dilakukan dalam dua acara baik offline dijual langsung kepada para penjual tanaman atau toko yang biasa menjual arang sekam dan briket, juga dilakukan pemasaran produk secara online melalui internet. Adapun rincian pemasaran dapat dilakukan dengan berbagai cara:

1. Memasang iklan digital (email, facebook, twitter, Instagram, dll) (Kotler \& Armstrong, 2018).

2. Memasang iklan di koran, katalog promosi, telepon, surat, juga mendatangi langsung pelanggan yang potensial
(Kotler \& Armstrong, 2018).

3. Mengenalkan produk melalui seminar dan pameran yang berkaitan juga memberikan produk gratis (sampel) (Huang, 2016).

4. Mencari calon konsumen di komunitas yang berhubungan dengan bisnis briket arang sekam (Kannan, Chang, \& Whinston, 1998).

5. Mencetak logo, kemasan yang menarik (Raheem, Vishnu, \& Ahmed, 2014).

6. Menyiapkan video tentang profil perusahaan (Kotler \& Armstrong, 2018).

Gambar 10 adalah contoh desain kemasan untuk produk briket arang sekam siap jual. Diharapkan dengan kemasan yang menarik dapat menarik perhatian calon pembeli.

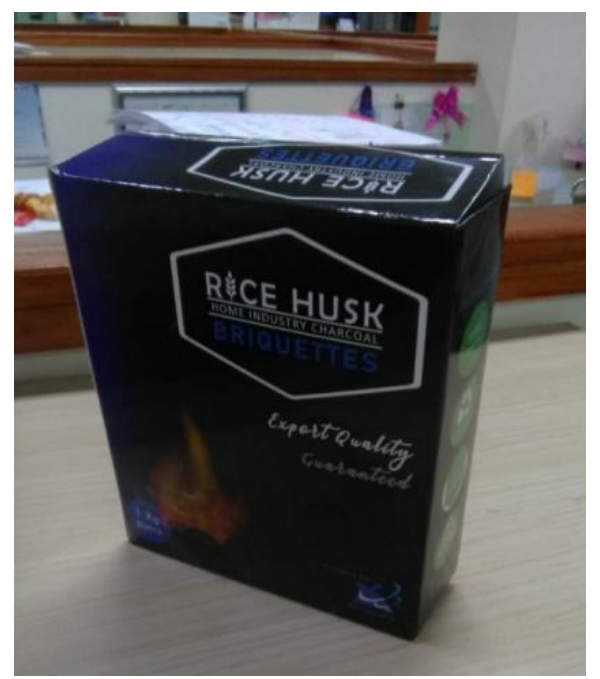

Gambar 10. Desain kemasan briket arang sekam

\section{SIMPULAN}

Penelitian ini dilakukan sebagai upaya memberikan solusi untuk memberikan tambahan pendapatan bagi masyarakat Desa Sukamaju, Kabupaten Bekasi. Salah satu caranya melalui pembuatan alat pembuat arang sekam dan mesin cetak briket arang sekam sederhana yang terjangkau, juga pengemasan dan cara pemasarannya untuk memanfaatkan limbah sekam padi menjadi produk briket arang yang bernilai jual lebih tinggi. 
Dengan membandingkan nilai jual sekam yang hanya Rp 1000 per kg dengan briket arang sekam yang berharga Rp 15.000 per $\mathrm{kg}$, serta kapasitas sebuah mesin cetak yang mampu memproduksi $120 \mathrm{~kg}$ per hari atau $3000 \mathrm{~kg}$ per bulan, maka potensi penghasilan masyarakat adalah $\mathrm{Rp}$ 45.000.000 per bulan.

\section{DAFTAR PUSTAKA}

Badan Pusat Statistik Kabupaten Bekasi. (2018). Kecamatan Tambelang Dalam Angka.

Baderan, D. W., \& Hamidun, M. S. (2016). Pemanfaatan Sekam Padi Sebagai Bahan Bakar Alternatif dan Pupuk Organik Yang Ramah Lingkungan Di Desa Lakeya Kecamatan Tolangohula Kabupaten Gorontalo.

Bono, Wahyono, \& Burhani, M. . (2017). Analisis Konsumsi Batubara Spesifik Ditinjau dari Nilai Kalor Batubara dan Perubahan Beban di PLTU Tanjung Jati B Unit 2. Eksergi Jurnal Teknik Energi, 13(2), 50-53.

Cahyono, J. F. (2017). Perancangan Alat Pencetak Briket Arang Sekam Padi Berkapasitas $180 \quad$ Briket/Jam. Universitas Muhammadiyah Malang.

Huang, H. C. (2016). How does meetings, incentives, conventions, and exhibitions industry attract exhibitors? Asia Pacific Journal of Tourism Research, 21(1), 73-93.

Kannan, P. K., Chang, A. M., \& Whinston, A. B. (1998). Marketing information on the I-way. Communication of the Association for Computing Machinery, Inc., 41(3).

Kotler, P., \& Armstrong, G. (2018). Principles of Marketing (Seventeent). United States: Pearson Education.

Mandey, L. C., \& Tarore, D. (2015). Pengembangan Produksi Biobriket Dari Limbah Hasil Pertanian Sebagai Bahan Bakar Pengganti Minyak Tanah dan Gas. Jurnal Ilmu Dan Teknologi Pangan, 3(2), 1-7.
Nurhilal, M., \& Tarigan, R. A. P. (207AD). Karakteristik Briket Arang Sekam Padi dan Arang Kulit Bawang Putih. Media Teknika Jurnal Teknologi, 12(2), 67-79.

Papilo, P. (2012). Briket pelepah kelapa sawit sebagai sumber energi alternatif yang bernilai ekonomis dan ramah lingkungan. Jurnal Sains, Teknologi Dan Industri, 9(2), 67-78.

Patabang, D. (2012). Karakteristik Termal Briket Arang Sekam Padi Dengan Variasi Bahan Perekat. Jurnal Mekanikal, 3(2), 286-292.

Raheem, A. R., Vishnu, P. A. R. M. A. R., \& Ahmed, A. M. (2014). Impact of product packaging on consumer's buying behavior. European Journal of Scientific Research, 122(2), 125-134.

Rahmiati, F., Amin, G., \& German, E. (2019). Pelatihan Pemanfaatan Limbah Padi Menjadi Arang Sekam Untuk Menambah Pendapatan Petani. Agrokreatif: Jurnal Ilmiah Pengabdian Kepada Masyarakat, 5(2), 159-164.

Sulmiyati, S. N. (2017). Pengolahan Briket Bio-Arang Berbahan Dasar Kotoran Kambing dan Cangkang Kemiri di Desa Galung Lombok, Kecamatan Tinambung, Polewali Mandar. Jurnal Pengabdian Kepada Masyarakat, 3(1), 108-117.

Suparni. (2020). Kementan Terus Galakkan Pengendalian Ramah Lingkungan Untuk Atasi Hama Sundep dan Beluk. Retrieved September 30, 2020, from http://ditlin.tanamanpangan.pertanian. go.id/berita/137

Suryaningsih, S., Resitasari, R., \& Nurhilal, O. (2019). Analysis of Biomass Briquettes Based on Carbonized Rice Husk and Jatropha Seed Waste by Using Newspaper Waste Pulp as an Adhesive Material. In Journal of Physics: Conference Series (Vol. 1280, p. 022072). OIP Publishing. 